\title{
ESPACIALIZAÇÃO DOS ATRATIVOS TURÍSTICOS DO PORTAL DE TURISMO DE NOVA VENEZA, SANTA CATARINA: UM ENSAIO
}

\section{TOURIST ATTRACTIONS SPATIALIZATION OF THE NOVA VENEZA, SANTA CATARINA TURIST PORTAL: AN ESSAY}

\section{André Fabiano M. Mastella \\ Geógrafo e Mestre em Gestão Territorial. Programa de Pós- Graduação em Engenharia de Transportes e Gestão Territorial - PPGTG Universidade Federal de Santa Catarina - UFSC. E-mail: \\ a.f.m.mastella@posgrad.u fsc.br}

\section{Jean Lucas P de Farias}

Engenheiro Agrimensor e Mestre em Gestão

Territorial. Programa de Pós-Graduação em Engenharia de Transportes e Gestão Territorial - PPGTG Universidade Federal de Santa Catarina - UFSC. E-mail:

Jean.farias@posgrad.ufsc. br

\section{RESUMO}

O objetivo do artigo é espacializar os atrativos turísticos do Portal de Turismo de Nova Veneza-SC bem como analisar sua interface e informações relativas à essas atrações. Foi utilizado uma abordagem exploratória e descritiva nos documentos relativos em ao Portal de Turismo de Nova Veneza-SC. Por fim, criou-se, a partir de um SIG livre, um mapa pontual georreferenciado dos atrativos turísticos elencados no Portal de Turismo. Conclui-se que, a partir dos resultados, o Portal de Turismo de Nova Veneza-SC apresenta 24 (vinte e quatro) atrações e precisa utilizar a cartografia temática a fim de produzir um mapa pontual pictórico georreferenciado dos atrativos turísticos do município para o munícipe, bem como aos turistas, já que o mapa criado se mostrou bastante interativo.

Palavras-chave: Turismo, Portal de Turismo, Cartografia temática

\section{ABSTRACT}

The aim of the article is to spatialize the tourist attractions of the Tourism Portal of Nova Veneza-SC as well as analyze its interface and information related to these attractions. An exploratory and descriptive approach was used in the relative documents in the Tourism Portal of Nova Veneza-SC. Finally, from a free GIS, a georeferenced point map of the tourist attractions listed in the Tourism Portal was created. It is concluded that, from the results, the New Venice-SC Tourism Portal presents 24 (twenty-four) attractions, and needs to use thematic cartography in order to produce a georeferenced pictorial point map of the municipality's tourist attractions for the city as well as tourists, as the map created was very interactive. Keywords: Tourism, Tourism Portal, Thematic Cartography 


\section{INTRODUÇÃO}

O turismo vai além da percepção comum limitado às atividades de lazer, viagens fora da cidade de origem ou viagens de $24 \mathrm{~h}$ a negócios ou outros propósitos. Em determinados municípios do Brasil, por exemplo, o turismo é a única fonte de renda da população. Dessa forma, políticas voltadas ao fomento do turismo visando incentivar e promover os pequenos negócios locais e valorizar os atrativos dos municípios e suas belezas naturais, além do cuidado com o meio ambiente, são fundamentais.

Conforme Silva, Costa e Carvalho (2013), a criação do Ministério do Turismo, no ano de 2003, pode ser citada como um marco recente dos investimentos na organização e administração da atividade turística no país com a missão de desenvolver o turismo como atividade econômica com papel relevante na geração emprego e renda, de forma sustentável, proporcionando inclusão social.

Ainda conforme Silva, Costa e Carvalho (2013), para que haja o fortalecimento da atividade turística, deve-se entender por política de turismo o conjunto e fatores condicionantes e de diretrizes básicas que expressam os caminhos para atingir os objetivos globais para o turismo do país, determinando as prioridades da ação executiva, supletiva ou assistencial do Estado.

Conforme Trindade, César e Vianna (2019), o turismo como atividade socioeconômica, cultural e ambiental, que envolve a interação entre turistas, comunidades e o ambiente (tanto físico, envolvendo a parte ecológica e a construída, quanto o social), demandam a estruturação e organização do setor, bem como a articulação de diversos atores.

Fazer um levantamento das potencialidades e prioridade da localidade, para só então estabelecer metas e objetivos alinhados à política nacional de turismo, é de fundamental importância para a decisão do futuro do setor turístico no país. Dessa forma, a política pública torna-se o vetor de direcionamento do processo de planejamento (SILVA; COSTA; CARVALHO, 2013).

Não obstante, o turismo deve estar alicerçado aos conceitos de paisagem e lugar, além do componente histórico, no espaço geográfico. Conforme Costa e Santos (2018), é o investimento turístico ou a intervenção com o intuito de criar produtos ou elementos de oferta turística que promove novas funções e recria formas antigas, contribui para a construção de novos equipamentos com funções específicas.

Para aliar o território ao desenvolvimento, Trindade, César e Vianna (2019) e Silva, Costa e Carvalho (2013) demandam uma maior eficiência na busca de uma gestão compartilhada, considerando-se indicado organizar e implantar um sistema público de turismo, cuja composição ideal seria formada por um conselho de turismo, por fundos de financiamento e por agências de desenvolvimento, a serem cumpridas a longo e médio prazo. 
Essas ações necessitam ser voltadas à preservação do meio ambiente, à garantia de adequados retornos econômicos e à melhoria de indicadores socioculturais e políticos, que dependem de uma variedade de agentes (governos, organizações não governamentais, empresas, turistas, comunidade local) e elementos (atrações turísticas, hospedagem, outros equipamentos turísticos e serviços, transporte, infraestrutura e elementos institucionais).

Uma forma de aliar Turismo e políticas de turismo, é através dos mapas. A cartografia temática, nesse caso, mostra-se uma importante ferramenta/técnica facilitadora na visualização dos indicadores socioeconômicos, a partir de mapas que descrevem aspectos sociais, culturais e econômicos.

Conforme Rosa (2011), seu uso para dados socioeconômicos vem descrever com números e informações concretas, as condições de uma determinada localização geográfica e sua incidência em determinado momento (geralmente os dados socioeconômicos são coletados dentro de limites administrativos). Conforme Rosolem et al. (2016), a partir do mapa temático têm-se a combinação de elementos como escala, projeção, tratamento dos dados, simbolização e cor. Todos eles, construídos a partir do mapa base, de fundo, e de sua camada de conteúdo e/ou temática.

Desta forma, os mapas socioeconômicos, conforme Loch (2006) e o Centro Popular de Cultura e Comunicação - CPCC (2016), podem ser representados através de variáveis visuais como tamanho, valor, saturação, orientação, granulação ou textura, dentre outros, além de elencar tudo que a população do território mapeado está ou não produzindo, consumindo, localização de indústrias, comércios, serviços, questões de saúde, dentre outros.

\section{JUSTIFICATIVA E OBJETIVOS}

O município de Nova Veneza-SC (Figura 1), berço da cultura italiana no sul do Brasil, marcado pela rota gastronômica italiana e com vários atrativos paisagísticos antrópicos e naturais, possui várias informações dispersas em relação aos atrativos turísticos, seja em blogs, sites, monografias, dissertações e teses, além do Portal de Turismo de Nova Veneza-SC. Durante a elaboração desse trabalho, buscou-se na WWW, produtos cartográficos referentes aos pontos turísticos do município, onde foi possível encontrar dois (2) mapas turísticos, similares ao encontrado no Pórtico de Entrada do município. $\mathrm{O}$ primeiro apresenta baixa qualidade (https://www.thinglink.com/scene/783866523511947266). Já

o segundo (https://www.coroflot.com/clesio/Mapa-tur\%C3\%ADstico-Nova-Veneza) apresenta boa qualidade, além da descrição dos pontos turísticos, elaborado por Clesio Amador.

Ainda foi buscado na WWW, no Mapa do Turismo de Santa Catarina (www.mapa.turismo.gov.br), informações turísticas sobre Nova Veneza-SC, mas não foram 
encontrados atrações e/ou rotas relacionadas ao turismo. Assim sendo, foram levantadas duas hipóteses: a primeira é de que o mapa turístico existe, tanto no município quanto na WWW, mas não possui publicidade. A segunda é de que as informações contidas nesses mapas são meramente ilustrativas e precisam estar georreferenciadas, com a rota dos pontos turísticos bem definidas para que munícipes e turistas identifiquem/localizem com precisão esses pontos turísticos.

Diante do exposto, o objetivo do artigo é analisar o Portal de Turismo do município de Nova Veneza-SC, mostrando a interface do portal (Figura 6), a tabulação dos pontos turísticos do Portal com suas coordenadas (Tabela 1) e a confecção de um produto cartográfico georreferenciado, espacializando, assim, esses pontos turísticos (Figura 7).

\section{METODOLOGIA}

O estudo seguiu uma abordagem indutiva (observação de casos concretos, comparando-os com a finalidade de descobrir as relações existentes entre eles), básica (gerar conhecimentos novos uteis, mas sem aplicação prévia prevista), qualitativa (dados analisados indutivamente), de caráter exploratória (estudo de caso, bibliográfico e documental) e descritiva (MOREIRA, 1999; SILVA e MENEZES, 2001; LAKATOS, 2003; GIL, 2008). A metodologia da pesquisa foi aplicada ao município de Nova Veneza (Figura 1).

\section{ÁREA DE INTERESSE}

O município de Nova Veneza (Figura 1), localizado no extremo sul do Estado de Santa Catarina (2838'12"S; 49²9'52"O) faz parte da Associação dos Municípios da Região Carbonífera AMREC e limita-se ao norte com Siderópolis, ao sul com Meleiro, a leste com Criciúma e Forquilhinha, a sudoeste e oeste com Morro Grande, e a noroeste com Bom Jardim da Serra e São José dos Ausentes (RS), e fica a 197 km da capital do estado, Florianópolis (MASTELLA, 2017).

Existem diferentes trajetos para se chegar à Nova Veneza-SC, porém o mais comum é o acesso rodoviário por meio da Rodovia Mário Covas, mais conhecido por BR 101, que faz conexão com a SC 455 (Rodovia Deputado Paulino Búrigo) no território de Içara, chegando até Criciúma (GONÇALVES, 2018). Ainda conforme Gonçalves (2018), a partir de Criciúma, segue-se pela Avenida Jorge Elias de Lucca, seguindo diretamente para Avenida Centenário e Rua Álvaro Catão, que faz a conexão rodoviária com Nova Veneza. Em Nova Veneza, utiliza-se a Avenida Luiz Lazzarin, a Rodovia José Spillere e a SC 446 (Rodovia Governador Irineu Bornhausen) para acessar a região central do território. 
Figura 1. Mapa de localização do município de Nova Veneza-SC

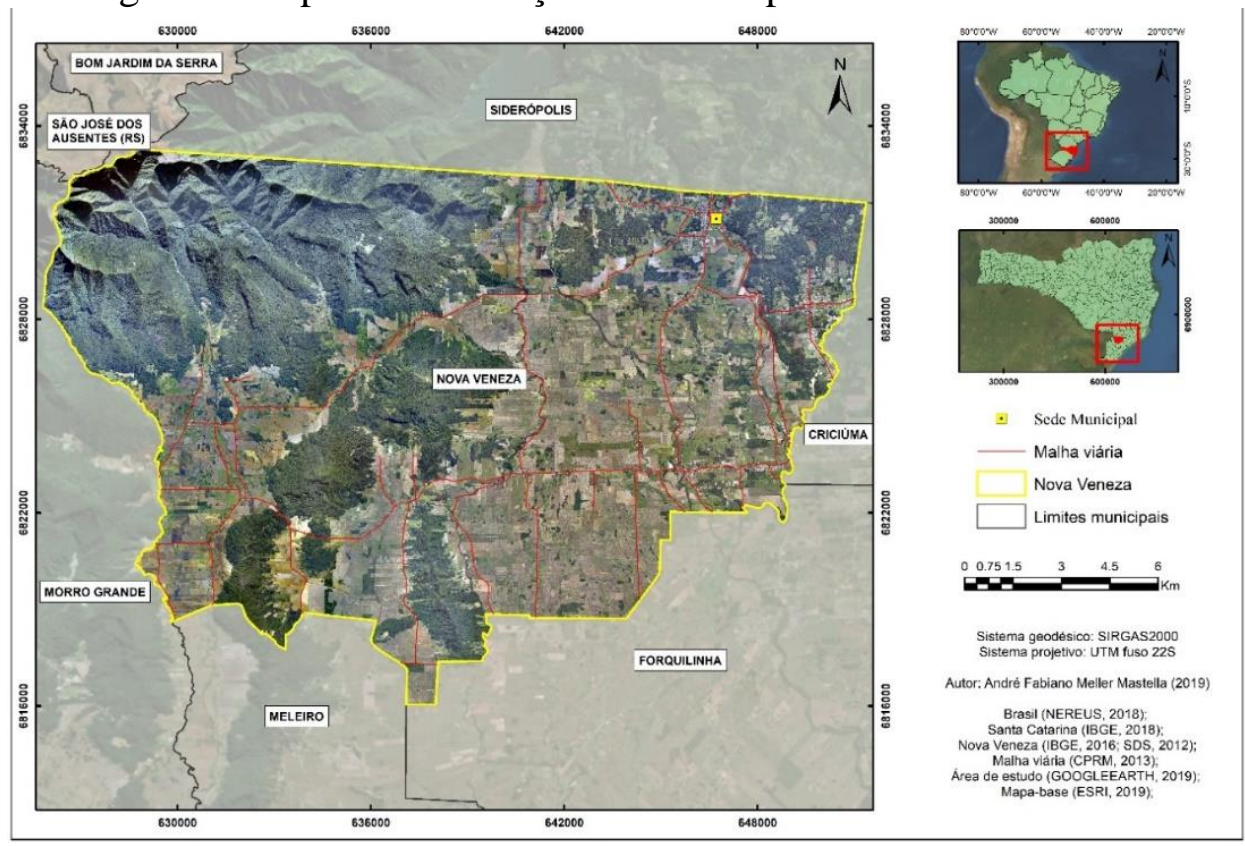

Fonte: Mastella (2019).

Quanto ao uso e cobertura da Terra - UCT, Nova Veneza é divido em urbano e rural, como pode ser visto no mapa em escala 1:120.000, na Figura 2. O UCT baseia-se na rizicultura, mineração de argila e seixos, pastagens, pecuária, milho, fumo, feijão, aviários e indústrias. $\mathrm{O}$ uso dos recursos hídricos destina-se à agricultura (arroz), indústrias e consumo humano. Por conseguinte, há conflitos de abastecimento humano versus agricultura, entre produtores rurais, poluição do rio Mãe Luzia e mineração (britador) de argilas e seixos (DIAS e ADAMI, 2009; MASTELLA, 2017).

Figura 2. Divisão municipal em urbano e rural, de acordo com os setores censitários do IBGE (2010)

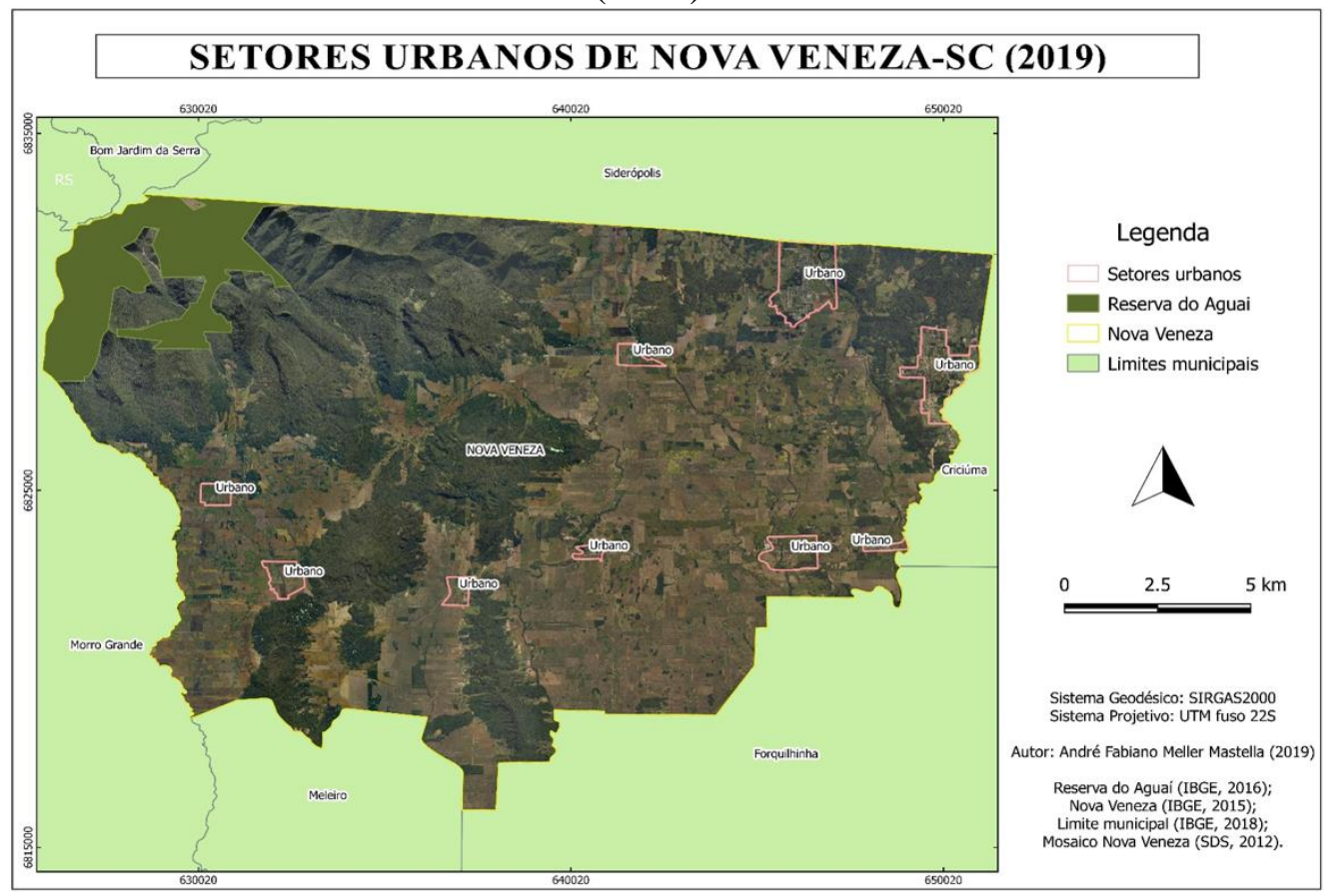

Fonte: Mastella (2019). 
Sua agricultura, com a expansão do cultivo de arroz irrigado, necessitou de uma demanda maior de água, intensificando o processo de poluição devido ao grande uso de agrotóxicos que contribuíram para a concentração de metais nas águas superficiais (MASTELLA, 2017). Já na parte noroeste de Nova Veneza, o material de origem dos solos é predominantemente proveniente dos processos erosivos da escarpa Serra Geral e a deposição desse material se deu por ação fluvial, ocasionando a rizicultura (BACK, 2015).

O UCT, no tocante a áreas desertificadas, pelo Censo Agropecuário de 2006, realizado pelo IBGE (IBGE, 2019), somam 21 hectares, bem como 29 hectares no tocante à pedreiras. Além disso, 463 hectares destinam-se a benfeitorias (obras) ou caminhos. Importante frisar a vulnerabilidade dos aquíferos, que está intimamente ligada às características do solo que influenciam na infiltração e na atenuação de poluentes (BACK, 2015).

Quanto ao uso da vegetação, o município possuía, em 2015, 308 hectares de produtos da silvicultura, dentre eles eucalipto (300 ha), pinus (6 ha) e outras espécies (2 ha), perfazendo um total de $23.400 \mathrm{~m}^{3}$ de madeira em tora. Utiliza, ainda, segundo Censo Pecuário de 2015 (IBGE, 2017), pastagem para aproximadamente 6.015 cabeças de gado (87 hectares) (IBGE, 2017). Por fim, Nova Veneza conta com 29 ha de lavouras permanentes, e 8.636,52 hectares de lavouras temporárias. Sua floresta natural corresponde a 90 ha, matas ou florestas naturais destinadas à preservação permanente ou reserva legal correspondem a 2.813 ha, e florestas plantadas, 926,1 ha (IBGE, 2017).

Na Figura 3 é possível observar um mapa de UCT, a partir de uma imagem Landsat 8, por uma classificação supervisionada por objeto, escala 1:130.000, para quatro (4) classes informacionais: Floresta, Culturas agrícolas, Solos expostos e Pastagem. O mapa possui $74.57 \%$ de exatidão global (MASTELLA, 2017).

A classe mascarada representa a área urbana e hidrografia. Esses atributos foram retirados para não prejudicar a classificação. A parte noroeste, norte, nordeste, centro-oeste e sudoeste é classificada majoritariamente por Floresta. Na parte noroeste também é possível encontrar a Reserva Biológica Estadual do Aguaí (polígono amarelo). Em seguida têm-se a classe Culturas Agrícolas classificadas às regiões norte, leste, centro-leste, sudeste e sudoeste. A classe Solos Expostos está em maior evidência nas porções centro-leste e sudoeste. Por fim, a classe Pastagem encontra-se em maior quantidade nas porções nordeste, sul e bordas/adjacências da classe floresta (MASTELLA, 2017).

Para outros aspectos como clima, geologia, geomorfologia, vegetação e hidrografia, ver Mastella (2017). Para mais questões envolvendo o UCT do município, ver a plataforma API Google Earth Engine (https://earthengine.google.com/), que disponibiliza um imenso catálogo de imagens de satélite, mosaicos classificados, índices de vegetação etc. 
Figura 3. Mapa de UCT a partir de uma imagem Landsat 8, mostrando quatro (4) classes informacionais, com $74.57 \%$ de exatidão global.

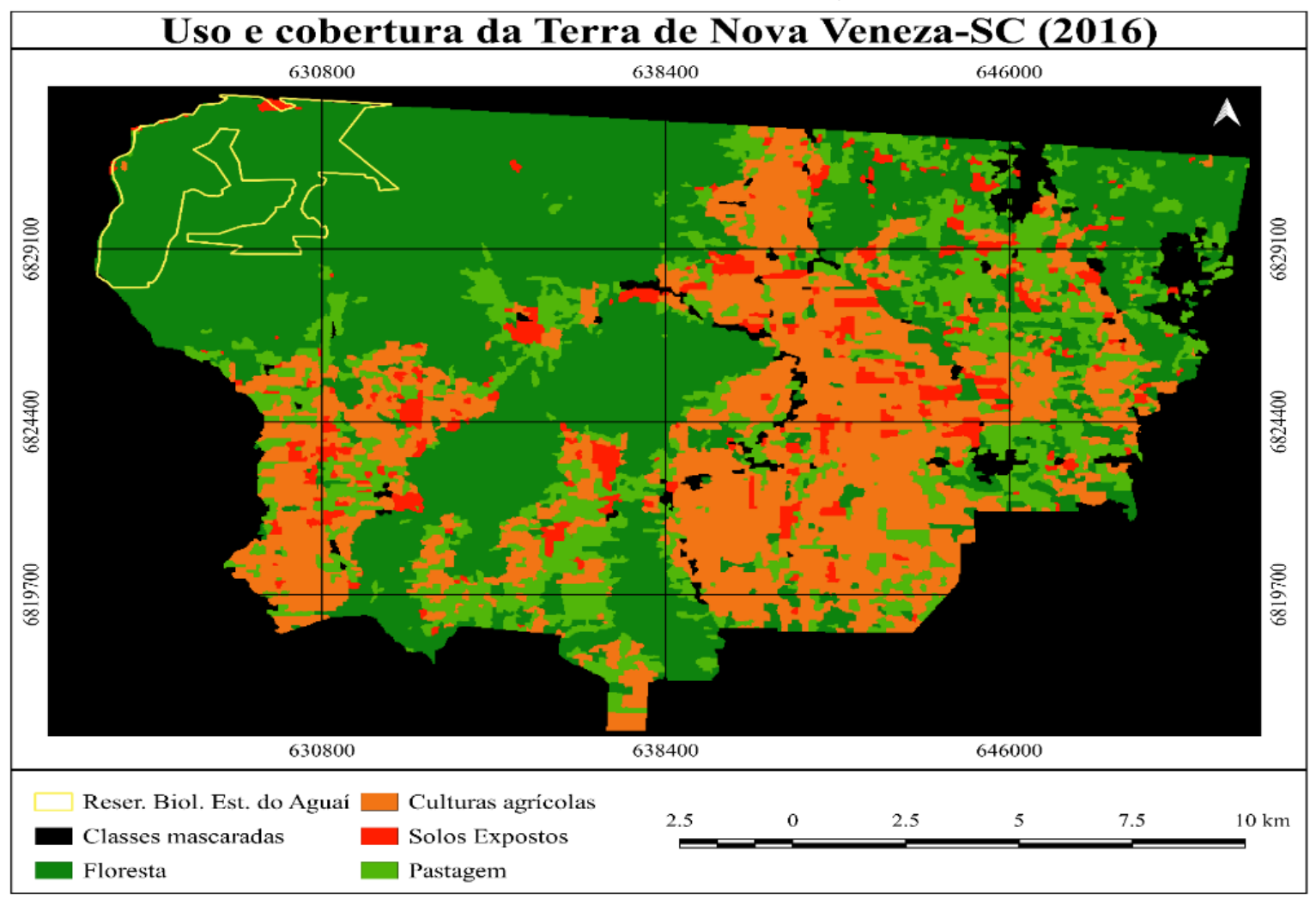

Fonte: Mastella (2017).

Quanto aos aspectos socioeconômicos, Nova Veneza possui uma área de 295,220 km², 71,6\% de esgotamento sanitário adequado, 6,2\% de arborização em vias públicas, e 13,5\% de urbanização de vias públicas, 14.987 habitantes, e 45,11 hab/km² (IBGE, 2019).

A tipologia dos imóveis do município constitui-se de $84 \%$ próprios, 12,6\% alugados, 3,2\% cedidos e $0,1 \%$ em outra condição. Quanto ao consumo, o consumo per capital urbano foi de $\mathrm{R} \$ 13.261,93$ reais, contra $\mathrm{R} \$ 7.623,31$ reais do rural (SEBRAE, 2013).

No que se refere aos aspectos sociais, Nova Veneza tem um Índice de Desenvolvimento Humano - IDH de 0,813. Já o índice de GINI, que mede a concentração de renda em determinado grupo, variando de zero a um, alcançou 0,402, e um total de 790 empresas (SEBRAE, 2013). Em relação à infraestrutura, em 2012, o município possuía 8.730 veículos, possuindo telefonia fixa, móvel e internet móvel 3G (hoje, 4G) (SEBRAE, 2013).

Em relação à Cultura, em Nova Veneza-SC têm-se o Plano Municipal de Cultura. Ele é um instrumento estratégico que organiza, regula e norteia a execução da Política Municipal de Cultura na perspectiva do Sistema Municipal de Cultura - SMC.

A elaboração do Plano Municipal de Cultura - PMC e dos Planos Setoriais de âmbito municipal é de responsabilidade da Secretaria Municipal de Cultura, Esporte e Turismo - SECET e 
Instituições Vinculadas, que, a partir das diretrizes propostas pela Conferência Municipal de Cultura - CMC, desenvolve Projeto de Lei a ser submetido ao Conselho Municipal de Política Cultural CMPC e, posteriormente, encaminhado à Câmara de Vereadores (NOVA VENEZA, 2019).

São ações da Secretaria Municipal de Cultura Projetos e Ações como o "Dolce Páscoa”, "Festa da Gastronomia Típica Italiana", "Carnevale di Venezia”, "Primavera em Nova Veneza" e "Natal de Nova Veneza" (NOVA VENEZA, 2019). Em relação ao turismo, Nova Veneza recebeu do governo estadual, através da Lei 12.789, o título de Capital Catarinense da Gastronomia Típica Italiana, destacando-se no cenário regional também pelo turismo gastronômico. Outra atividade que vem crescendo no município é o cicloturismo (GONÇALVES, 2018).

O município ainda possui um site, o Portal de Turismo de Nova Veneza-SC (https://turismo.novaveneza.sc.gov.br), com informações sobre o município, bem como os pontos turísticos gastronômicos, hoteleiros e paisagísticos de Nova Veneza-SC. Destacam-se o Museu do Imigrante, as Casas de Pedra, Gôndola Lucile etc.

Para maiores questões sobre turismo, ver Gonçalves (2018). Para maiores detalhes sobre o Portal, Figura 6 além da Figura 7, onde mostra o mapa pontual das atrações turísticas do município.

\section{MATERIAIS E MÉTODOS}

Para essa pesquisa foram utilizados os seguintes materiais:

a) Documentação: Informações turísticas disponibilizadas pelo Portal de Turismo de Nova Veneza-SC (https://turismo.novaveneza.sc.gov.br).

b) Produtos vetoriais: Arquivos vetoriais do município de Nova Veneza-SC (malha viária, limites municipais, hidrografia), disponibilizados livremente pelo Instituto Brasileiro de Geografia e Estatística - IBGE (https://downloads.ibge.gov.br/downloads_geociencias.htm), para confecção do produto cartográfico (Figura 7).

c) Softwares: Google Earth para coleta das coordenadas UTM (X,Y) dos pontos turísticos com base nos dados do Portal de Turismo de Nova Veneza-SC;

d) Microsoft Excel 2019, para tabulação das coordenadas dos pontos turísticos e posterior exportação da Tabela 1, em formato .csv, ao ambiente SIG livre para criação do produto cartográfico (Figura 7);

e) SIG livre QGIS Las Palmas, versão 2.18.19, utilizado para confeccionar o mapa pontual georreferenciado dos atrativos turísticos do município de Nova Veneza (Figura 7). A Figura 4, apresenta o fluxograma metodológico das tomadas de decisão acerca da pesquisa. 
Figura 4. Fluxograma metodológico acerca da pesquisa.

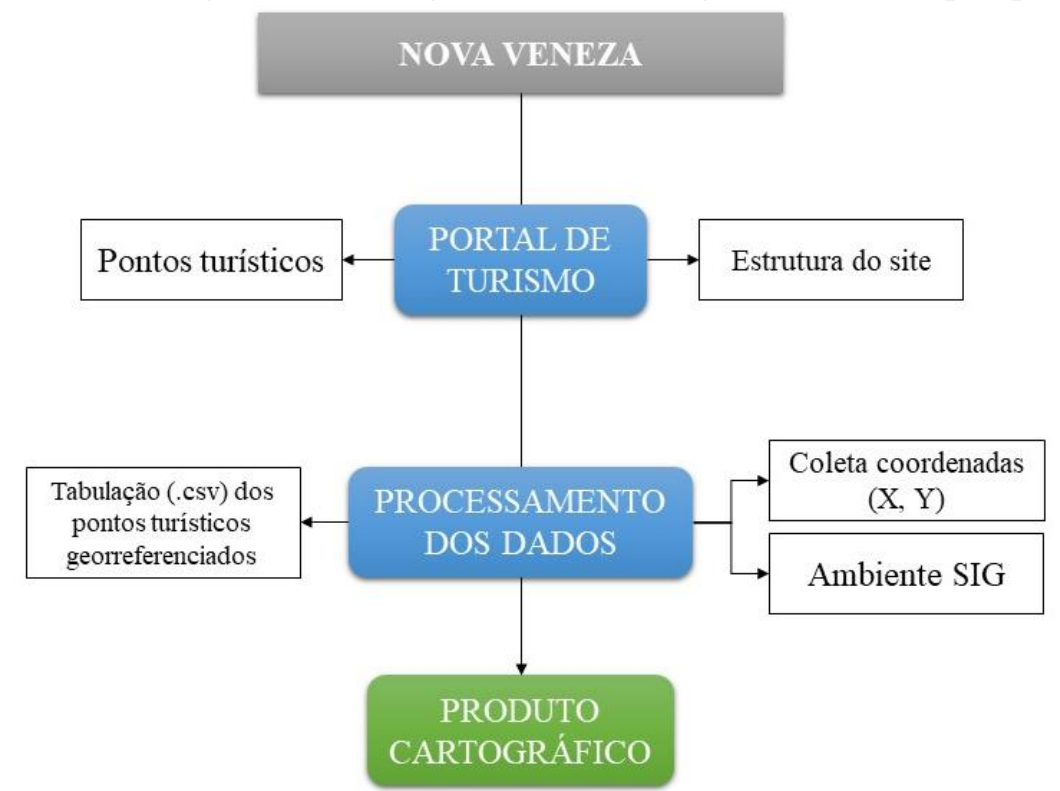

Fonte: Elaborado pelos autores (2019).

Em relação ao Portal de Turismo de Nova Veneza-SC (Figura 6), analisou-se a estrutura do site (https://turismo.novaveneza.sc.gov.br/) e a disposição dos atrativos turísticos, a hierarquização das informações (hotelaria, gastronomia, pesque-pague), mapas de localização, estrutura organizacional etc.

Todos os atrativos turísticos foram tabulados (Tabela 1), totalizando 24 (vinte e quatro) pontos turísticos, conforme descritos no Portal de Turismo de Nova Veneza (https://turismo.novaveneza.sc.gov.br), que raras exceções trabalham em conjunto ao serviço de mapeamento Google Maps.

Foram catalogados o nome do ponto turístico bem como a sua coordenada altimétrica e planimétrica UTM (X,Y), coletadas a partir do software Google Earth. Algumas coordenadas foram obtidas pesquisando o ponto turístico na internet, e a partir do serviço de mapas Google Maps, identificou-se o local, navegando-se no software Google Earth, até o ponto, obtendo-se assim a coordenada. A Tabela 1 apresenta os pontos turísticos, bem como sua coordenada UTM.

Tabela 1. Pontos turísticos catalogados, com nome e coordenada UTM.

\begin{tabular}{clll}
\hline ID & Nome & X & Y \\
\hline 1 & Aguaí Santuário Ecológico & $641040 \mathrm{E}$ & $6833859 \mathrm{~N}$ \\
2 & Artesanato Arte Veneza & $646696 \mathrm{E}$ & $6831258 \mathrm{~N}$ \\
3 & Caminhos da Via-Crucis & $646973 \mathrm{E}$ & $6831454 \mathrm{~N}$ \\
4 & Carnevale di Venezia & $646773 \mathrm{E}$ & $6831309 \mathrm{~N}$ \\
5 & Casarios Antigos & $646686 \mathrm{E}$ & $6831223 \mathrm{~N}$ \\
6 & Casa de Pedra & $648319 \mathrm{E}$ & $6830697 \mathrm{~N}$ \\
7 & Chaminé & $646775 \mathrm{E}$ & $6831205 \mathrm{~N}$ \\
\hline
\end{tabular}




\begin{tabular}{|c|c|c|c|}
\hline 8 & Festa da Gastronomia & $646739 \mathrm{E}$ & $6831274 \mathrm{~N}$ \\
\hline 9 & Gastronomia Típica Italiana & $646696 \mathrm{E}$ & $6831284 \mathrm{~N}$ \\
\hline 10 & Gôndola Lucille & $646723 \mathrm{E}$ & $6831249 \mathrm{~N}$ \\
\hline 11 & Monumento ao Imigrante & $646934 \mathrm{E}$ & $6830706 \mathrm{~N}$ \\
\hline 12 & Monumento "Os Anjos" & $649596 \mathrm{E}$ & $6828463 \mathrm{~N}$ \\
\hline 13 & Museu do Imigrante & $646883 \mathrm{E}$ & $6831294 \mathrm{~N}$ \\
\hline 14 & Ponte Dei Morosi & $646611 \mathrm{E}$ & $6831292 \mathrm{~N}$ \\
\hline 15 & Pórtico de Entrada & $646963 \mathrm{E}$ & $6830648 \mathrm{~N}$ \\
\hline 16 & Praça Humberto Bortoluzzi & $646689 \mathrm{E}$ & $6831275 \mathrm{~N}$ \\
\hline 17 & Roda D'água & $646710 \mathrm{E}$ & $6831267 \mathrm{~N}$ \\
\hline 18 & Enoturismo & $646857 \mathrm{E}$ & $6831283 \mathrm{~N}$ \\
\hline 19 & Cachoeira da Vila Maria & $627218 \mathrm{E}$ & $6828301 \mathrm{~N}$ \\
\hline 20 & Cachoeira do Cantão & $637178 \mathrm{E}$ & $6831476 \mathrm{~N}$ \\
\hline & Cachoeira Três Quedas ou da & & \\
\hline 21 & Clínica & $635526 \mathrm{E}$ & $6829711 \mathrm{~N}$ \\
\hline 22 & $\begin{array}{l}\text { Igreja Matriz de São Marcos } \\
\text { Santuário Nossa Senhora de }\end{array}$ & $646855 \mathrm{E}$ & $6831254 \mathrm{~N}$ \\
\hline 23 & Caravaggio & $649684 \mathrm{E}$ & $6828424 \mathrm{~N}$ \\
\hline 24 & Pesque-pague Ghislandi & $647601 \mathrm{E}$ & $6829306 \mathrm{~N}$ \\
\hline
\end{tabular}

Após isso, as coordenadas dos pontos turísticos coletadas no Google Earth, tabuladas em ambiente Excel, foram exportados no formato ".csv" para o ambiente SIG, a partir da ferramenta "adicionar uma camada de texto delimitado", por “;” (ponto e vírgula).

No software SIG, junto aos dados vetoriais disponibilizados livremente pelo IBGE (malha viária, limite municipal, hidrografia), foi confeccionado um mapa pontual georreferenciado dessas variáveis (Figura 7), na tentativa de tornar os pontos turísticos interativos, inteligíveis e especializados ao munícipe e ao turista.

\section{RESULTADOS}

Nessa seção são apresentados os resultados em relação ao Portal de Turismo de Nova VenezaSC (Figura 6), com a interface do site, os pontos turísticos, a estrutura organizacional e o produto cartográfico (mapa pontual georreferenciado) a partir dos dados tabulados (Tabela 1) disponíveis no Portal (Figura 7).

\section{PORTAL DE TURISMO DE NOVA VENEZA-SC}

O Portal de Turismo de Nova Veneza-SC traz em sua página principal (https://turismo.novaveneza.sc.gov.br/) itens como "o que fazer", “onde comer", "onde ficar" e "sobre a cidade" (NOVA VENEZA, 2019).

O site elenca 24 (vinte e quatro) pontos turísticos, conforme a Tabela 1. A navegação é de forma interativa, onde o usuário tem a categoria desses pontos turísticos como "Cultura e História", 
"Natureza e Ecoturismo", "Negócios e Eventos", "Passeios e Aventura", "Turismo religioso" e “Turismo rural". A Figura 6 mostra como estão dispostos os pontos turísticos no Portal de Turismo de Nova Veneza-SC.

Figura 6. Interface do Portal de Turismo de Nova Veneza-SC mostrando os pontos turísticos por categoriais, como descritas nessa seção.

NAVEGAR

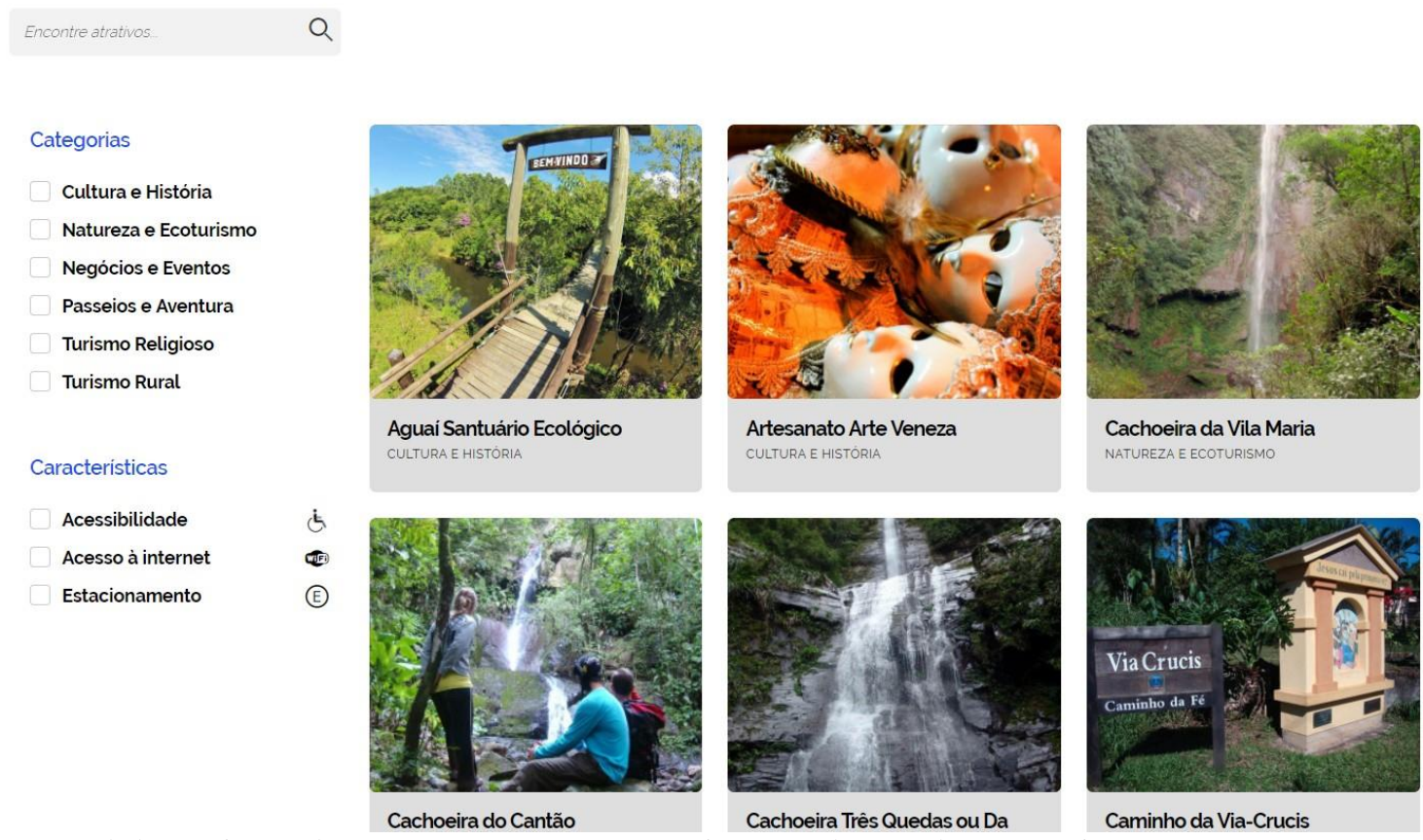

Fonte: Portal de Turismo de Nova Veneza (2019). Disponível em: 〈https://turismo.novaveneza.sc.gov.br〉. Acesso em: 21 ago. 2019.

Já na seção "Serviços", o município conta com 2 (dois) estabelecimentos catalogados referentes à alimentos e bebidas, 1 (um) estabelecimento referente à Associações, Cooperativas e Sindicatos, 1 (um) estabelecimento referente à Compras, e 1 (um) estabelecimento referente à Serviços turísticos. Este último, trata-se da "Roteiros do Sul", uma operadora de turismo receptivo que desenvolve produtos que abrangem toda região de entorno do município de Nova Veneza (NOVA VENEZA, 2019).

O site possui alguma interatividade com o serviço de mapas Google Maps, onde é possível calcular a distância das cidades até Nova Veneza-SC. Também possui links "como chegar de ônibus" e "como chegar de avião".

A partir desses pontos turísticos disponibilizados pelo Portal de Turismo de Nova Veneza-SC, foi possível criar, em ambiente SIG, um mapa pontual georreferenciado, facilitando a análise espacial das rotas e dos pontos turísticos de Nova Veneza-SC (Figura 7). Ao todo, são 24 (vinte e quatro) pontos turísticos (ver Tabela 1). 
Como é possível observar, as informações contidas no Portal do Turismo de Nova VenezaSC foram espacializadas e georreferenciadas num mapa pontual (Figura 7), onde constata-se as principais rotas aos pontos turísticos (Rota da Via-Crucis, Rota Reserva Aguaí etc.), fotos dos pontos turísticos, principais rodovias e cursos d'água (legenda). O mapa está em formato A3, escala 1:115.000. Para melhor visualização, seu download pode ser feito a partir deste link (https://www.dropbox.com/s/9ckhb0lqmr2jdnv/Mapa_turistico_Nova_Veneza_Mastella_2019.pdf? $\mathrm{dl}=0)$.

Figura 7. Mapa pontual com os pontos turísticos de Nova Veneza-SC, facilitando a visão espacial pelos munícipes e turistas.

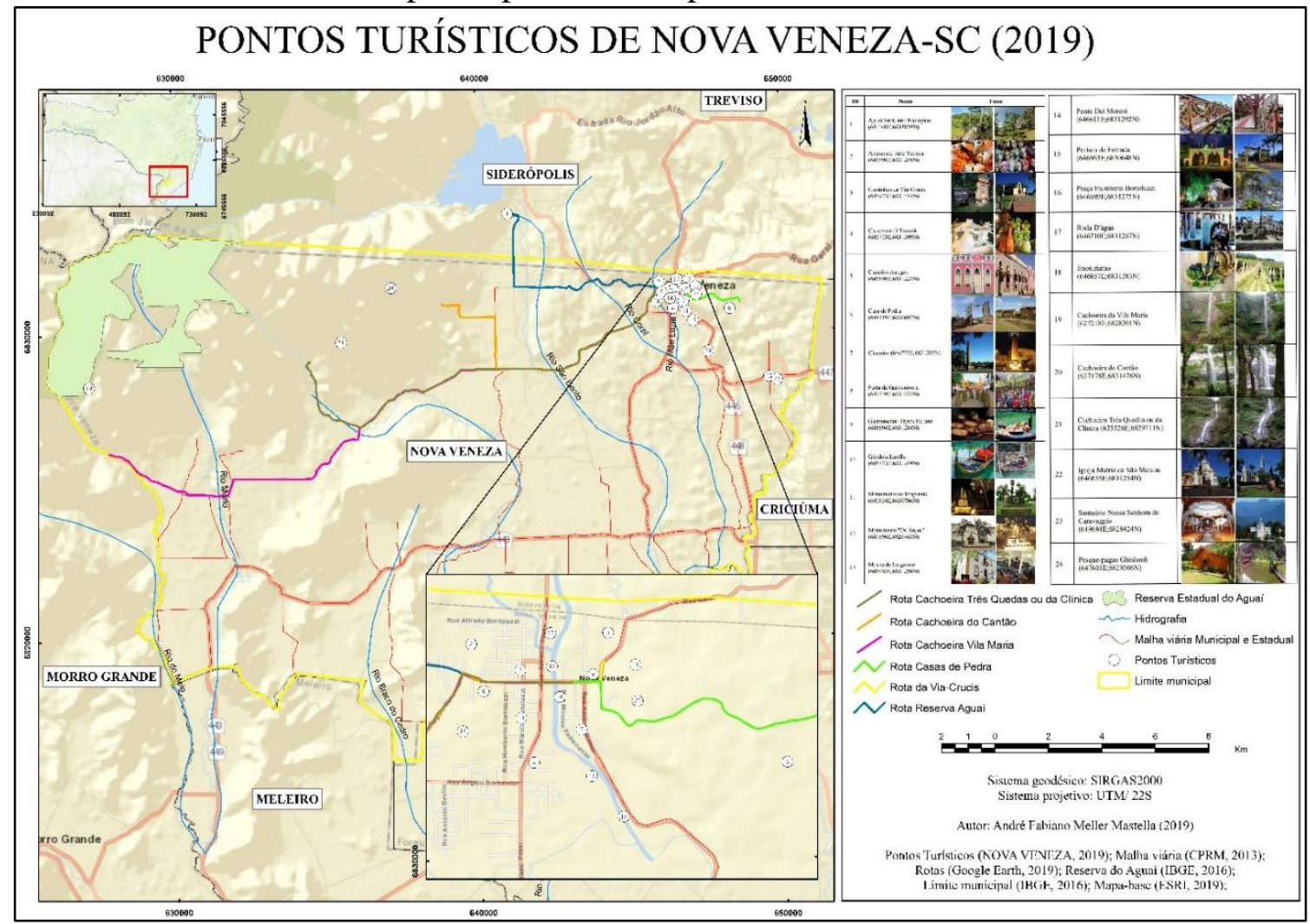

Fonte: Mastella (2019)

\section{ANÁLISE DOS RESULTADOS E CONSIDERAÇÕES FINAIS}

Em relação à área de estudo diante dos dados relativos ao UCT, o gestor municipal poderia estudar os mesmos para implantação de políticas públicas voltadas ao turismo. Para tal, sugere-se a elaboração de melhores mapas de UCT, em escala grande, para definição de políticas do Solo que vão de encontro às políticas turísticas fomentadas no Portal de Turismo.

Diante dos dados socioeconômicos que o município possui, a Secretaria de Cultura, Esporte e Turismo - SECET poderia fomentar projetos nas escolas, enfatizando a importância do turismo local, mostrando a importância das localidades, das áreas rurais, a criação de Reserva Particular do 
Patrimônio Natural - RPPN com vistas a gerar outras fontes de renda à população local etc. Dessa forma, novos atrativos turísticos poderiam ser incluídos no portal.

Quanto ao Portal de Turismo de Nova Veneza-SC, o mesmo possui uma boa interface com fotos, trabalha - raras exceções - em acordo ao serviço de mapas Google Maps. Porém, o Portal precisa confeccionar guias/mapas turísticos, bem como a distribuição de flyers a partir da sede municipal, ou junto ao Pórtico de Entrada do município (local onde fica o mapa turístico). Não obstante, deve-se trabalhar uma gestão compartilhada, onde Secretaria Municipal de Cultura, Esporte e Turismo - SECET e Portal de Turismo de Nova Veneza-SC criem ações para fomentar instrumentos de políticas públicas voltadas ao turismo. Sugere-se, assim, a criação de uma secretaria forte, com um turismólogo, e uma estrutura organizacional bem definida para estratégia e definição das rotas e mapas turísticos.

A SECET, juntamente com os gestores municipais, alinhavado às políticas públicas e ao Plano Diretor, precisa melhorar a distribuição turística, já que boa parte das atrações, como pode ser visto na Figura 7, concentram-se na parte norte, nordeste e noroeste do município. O cicloturismo, elencado por Gonçalves (2018), seria uma boa alternativa.

Sugere-se aos gestores a criação de um SIG Web, onde o munícipe, bem como o turista, tenha a possibilidade de traçar sua própria rota turística, podendo imprimir e exportar, assim, seus mapas. Como forma de incentivar o turista, também é interessante que existam aplicativos para dispositivos moveis no qual o usuário tivesse acesso as informações e interagisse com a administração pública quanto à gestão dos seus pontos turísticos.

Por fim, o mapa temático pontual mostrou-se uma ótima ferramenta para especializar os pontos turísticos, sendo uma boa abordagem para descrever as potencialidades turísticas e econômicas de Nova Veneza-SC (Figura 7). Além disso, o mapa trouxe maior inteligibilidade/noção espacial aos usuários, já que em nenhum órgão municipal foi possível encontrar dados georreferenciados em relação aos pontos turísticos. Espera-se que o mapa gerado (Figura 7) sirva de norte à SECET para confecção de outros produtos cartográficos em relação aos atrativos turísticos do município, e que os dados pictóricos dos mapas já confeccionados sejam georreferenciados.

\section{REFERÊNCIAS}

BACK, M. Vulnerabilidade do aquífero livre em leques aluviais do sul de Santa Catarina sob arroz irrigado / Marcos Back. - Tese (Doutorado). Programa de Pós-Graduação em Geografia. Universidade Federal de Santa Catarina - UFSC. Florianópolis, 2015. 458p

CENTRO POPULAR DE CULTURA E COMUNICAÇÃO - CPCC. Mapeamento Socioeconômico (2016). Disponível em: <https://www.slideshare.net/CPCCRADCOM/apresentaomapeamento-socioeconmico>. Acesso em: 22 ago. 2019. 
COSTA, C.; SANTOS, N. A paisagem enquanto produto turístico e patrimônio natural e cultural: o caso da Serra da Estrela. Cadernos de Geografia - n ${ }^{\circ}$ 38. Coimbra, 2018.

DIAS, A.O; ADAMI, R.M. Nossas águas: Relatório da oficina 1 - BH Araranguá. Piava Sul - Turvo, 2009. 24p.

GIL, A.C. Métodos e técnicas de pesquisa social. - 6. ed - São Paulo : Atlas, 2008.

GONÇALVES, M.L.R. O cicloturismo como uma ferramenta estratégica para o desenvolvimento territorial de Nova Veneza-SC. Dissertação (mestrado profissional). PósGraduação em Planejamento Territorial e Desenvolvimento. Universidade do Estado de Santa Catarina - UDESC. Florianópolis, 2018.

INSTITUTO BRASILEIRO DE GEOGRAFIA E ESTATISTICA - IBGE. Censo Agropecuário 2017: características dos estabelecimentos. Disponível em: <https://cidades.ibge.gov.br/brasil/sc/nova-veneza/pesquisa/24/27745>. Acesso em: 07 mai. 2019.

. Cidades: Nova Veneza (2019). Disponível em: <https://cidades.ibge.gov.br/brasil/sc/novaveneza>. Acesso em: 29 abr. 2019.

LAKATOS, E.M. Fundamento de metodologia científica. - 5. ed. - São Paulo: Atlas 2003.

LOCH, R. E. N. Cartografia: representação, comunicação, e visualização de dados espaciais / Ruth E. Nogueira Loch. - Florianópolis; Ed. da UFSC, 2006. 313p

MASTELLA, A.F.M. Avaliação da acurácia temática para classificação de imagens de satélite: estudo de caso no município de Nova Veneza-SC. Trabalho de Conclusão de Curso - TCC. Departamento de Geociências. Universidade Federal de Santa Catarina - UFSC. Florianópolis, 2017. MOREIRA, D.A. Etapas de uma dissertação de mestrado. Revista Álvares Penteado 2 , n 3 . São Paulo, 2001. ISSN 1517-7912

Prefeitura Municipal de Nova Veneza (2019). Disponível em: <https://www.novaveneza.sc.gov.br/>. Acesso em: 22 ago. 2019.

ROSA, R. Análise espacial em geografia. Revista da ANPEGE, v. 7, n. 1, número especial, p. 275 289, out. 2011.

ROSOLEM, G. P. N. et al. Análise das características socioeconômicas da mesorregião norte catarinense por meio de mapas temáticos. Anais do COBRAC 2016. Universidade Federal de Santa Catarina - UFSC. Florianópolis, 2016.

SERVIÇO BRASILEIRO DE APOIO ÀS MICRO E PEQUENAS EMPRESAS - SEBRAE. Santa Catarina em números: Nova Veneza. Sebrae/SC. Florianópolis, 2013.

SILVA, F.S.; COSTA, S.R.; CARVALHO, C.M.B. Políticas públicas de turismo no Brasil: estratégias para administração da atividade no país. X Simpósio de Excelência em Gestão e Tecnologia. Resende-RJ, 2013.

SILVA, E.L.; MENEZES, E.M. Metodologia da pesquisa e elaboração de dissertação. 3. ed. rev. atual. Laboratório de Ensino a Distância da UFSC. Florianópolis, 2001.

TRINDADE, B.S.; CÉSAR, P.A.B.; VIANNA, S.L.G. Governança do turismo: planejamento e gestão local e regional em Gramado-RS, Brasil. Rosa dos Ventos - Turismo e Hospitalidade. Caxias do Sul, 2019. 